\title{
Overweight Prevention Implemented by Primary School Teachers: A Randomised Controlled Trial
}

\author{
Susanne Brandstetter ${ }^{a} \quad$ Jochen Klenk $^{b}$ Swantje Berg ${ }^{c, d} \quad$ Christoph Galm ${ }^{d}$ \\ Michael Fritz $^{\mathrm{e}}$ Richard Peter ${ }^{\mathrm{b}} \quad$ Dmytro Prokopchuk $^{\mathrm{a}}$ Ronald P. Steiner ${ }^{\mathrm{a}}$ \\ Olivia Wartha ${ }^{\mathrm{e}}$ Jürgen Steinacker ${ }^{\mathrm{a}}$ Martin Wabitsch $^{c}$ \\ aDivision of Sports and Rehabilitation, Department of Internal Medicine II - Cardiology,

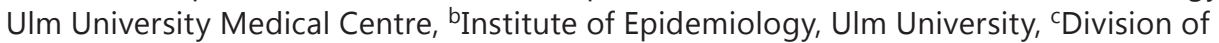 \\ Paediatric Endocrinology and Diabetes, Department of Paediatrics, Ulm University Medical \\ Centre, ${ }^{\mathrm{d} D i v i s i o n}$ of Paediatric Cardiology, Department of Paediatrics, Ulm University \\ Medical Centre, ${ }^{e}$ Transfercentre for Neuroscience and Learning (ZNL), Ulm University, Ulm, \\ Germany
}

\section{Key Words}

Behavioural interventions $\cdot$ BMI $\cdot$ Body composition $\cdot$ Children $\cdot$ Prevention

\begin{abstract}
Objective: To describe the effects of URMEL-ICE, a German school-based intervention for overweight prevention, on children's BMI and other measures of fat mass. Methods: A clusterrandomised controlled design was used. The intervention which focused on physical activity, TV time and soft drink consumption was integrated into a second-grade curriculum and was implemented by classroom teachers themselves. It comprised 29 teaching lessons, 2 short exercise blocks per day and 6 family homework lessons. BMI was assessed as primary outcome measure, waist circumference and skinfold thickness as secondary outcomes. Data of 945 children were analysed. Results: Multivariate analyses adjusted for baseline values showed no statistically significant effect of the intervention on BMI, but on waist circumference $(-0.85$; $95 \%$ confidence interval $(95 \% \mathrm{CI})-1.59$ to -0.12$)$ and subscapular skinfold thickness $(-0.64$; $95 \%$ CI -1.25 to -0.02 ). After additional adjustment for individual time lag between baseline and follow-up, these effects were reduced to -0.60 (95\% CI -1.25 to 0.05$)$ and -0.61 ( $95 \%$ CI -1.26 to 0.04$)$ and lost their statistical significance. Conclusion: This study contributes to the field of randomised school-based studies on overweight prevention and shows that within a 1-year, integrated intervention no effect on BMI, but a tendency towards effects on fat mass can be achieved.

Copyright (c) 2012 S. Karger GmbH, Freiburg
\end{abstract}

S. Brandstetter and J. Klenk contributed equally to this work. 


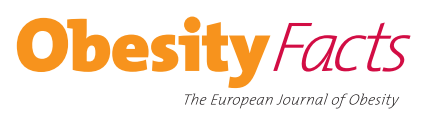

\begin{tabular}{l|l}
\hline \multicolumn{2}{l}{ Obes Facts 2012;5:1-11 } \\
\hline DOI: 10.1159/000336255 & $\begin{array}{l}\text { C 2012 S. Karger GmbH, Freiburg } \\
\text { www.karger.com/ofa }\end{array}$ \\
Published online: March 2, 2012 &
\end{tabular}

Brandstetter et al.: Overweight Prevention in Primary Schools

\section{Introduction}

High prevalences of overweight and obesity in childhood are still a major problem in most industrialised countries [1,2]. It has been reported that there are strong secular increases within 30 years in body fat, in normal-weight as well as in overweight children [3]. In Germany, the percentage of 7- to 10-year-old children who are classified as overweight has increased by $50 \%$ within the past 15 years $[4,5]$.

Even if initial studies report stagnation of prevalence and levelling-off of incidences [6], the necessity for successful primary prevention is commonly accepted. Overweight and obesity persist over time within childhood [7, 8] and into adulthood [9]. Efforts to treat them are troublesome and in the long run often ineffective [10].

Reviews agree that until now the evidence concerning the effectiveness of prevention programmes is insufficient [11-13], in part due to the limited number of methodologically well-designed studies [14]. Thus, there is a need for randomised-controlled trials of overweight prevention programmes with sufficient statistical power and suitable outcome measures.

Current literature provides several suggestions for successful overweight prevention: enhancement of physical activity [15], reduction of television time [16] and reduction of the consumption of sugar-sweetened beverages [17].

Schools in particular seem to be a powerful setting [18]. Possible barriers are low, so that all children can be reached easily. Children spend the main part of their day in schools, and teachers are the personnel qualified in dealing with children as well in considering their age-appropriate needs and competencies. From a public health perspective the role of schools for health promotion is very important. However, the high investment of time and resources may impede long-term implementation of intervention programmes [19-21]. Thus, the input from teachers is essential in developing health promotion measures that take into account their concerns as well those of the school into account.

URMEL-ICE (Ulm Research on Metabolism, Exercise, and Lifestyle Intervention in Children) [22, 23], a randomised-controlled trial on school-based overweight prevention, was designed with these methodological and practical considerations in mind. The intervention programme was developed together with experienced teachers to ensure anchoring within the existing curricular framework of elementary schools. It was implemented during regular classtime by the classroom teacher.

The objective of this paper is to report the effects of URMEL-ICE on BMI (primary outcome) and further measures of fat mass, since an effective intervention should slow down increases in all anthropometric parameters in the intervention group.

\section{Material and Methods}

Study Design

The URMEL-ICE study is a school-based, cluster-randomised intervention trial located in Ulm and adjacent regions in Southern Germany.

Sample size estimation was performed based on the primary outcome BMI. The assumed effect for the difference between intervention and control group after the intervention year was $0.1 \mathrm{~kg} / \mathrm{m}^{2}$ (SD 0.4 $\mathrm{kg} / \mathrm{m}^{2}$ ). After considering non-compliance and cluster randomisation, a total of 616 participants was calculated $(\alpha=0.05$, power $=0.8)$.

All principals of elementary schools within the Ulm region were informed in writing about the study (with support by the local Department of Education). They were asked to invite first-grade teachers to participate in the study. Teachers often consulted the pupils' parents before agreeing to participate. Teachers who had already implemented another intervention programme focusing on health behaviour were not included due to potential bias. 


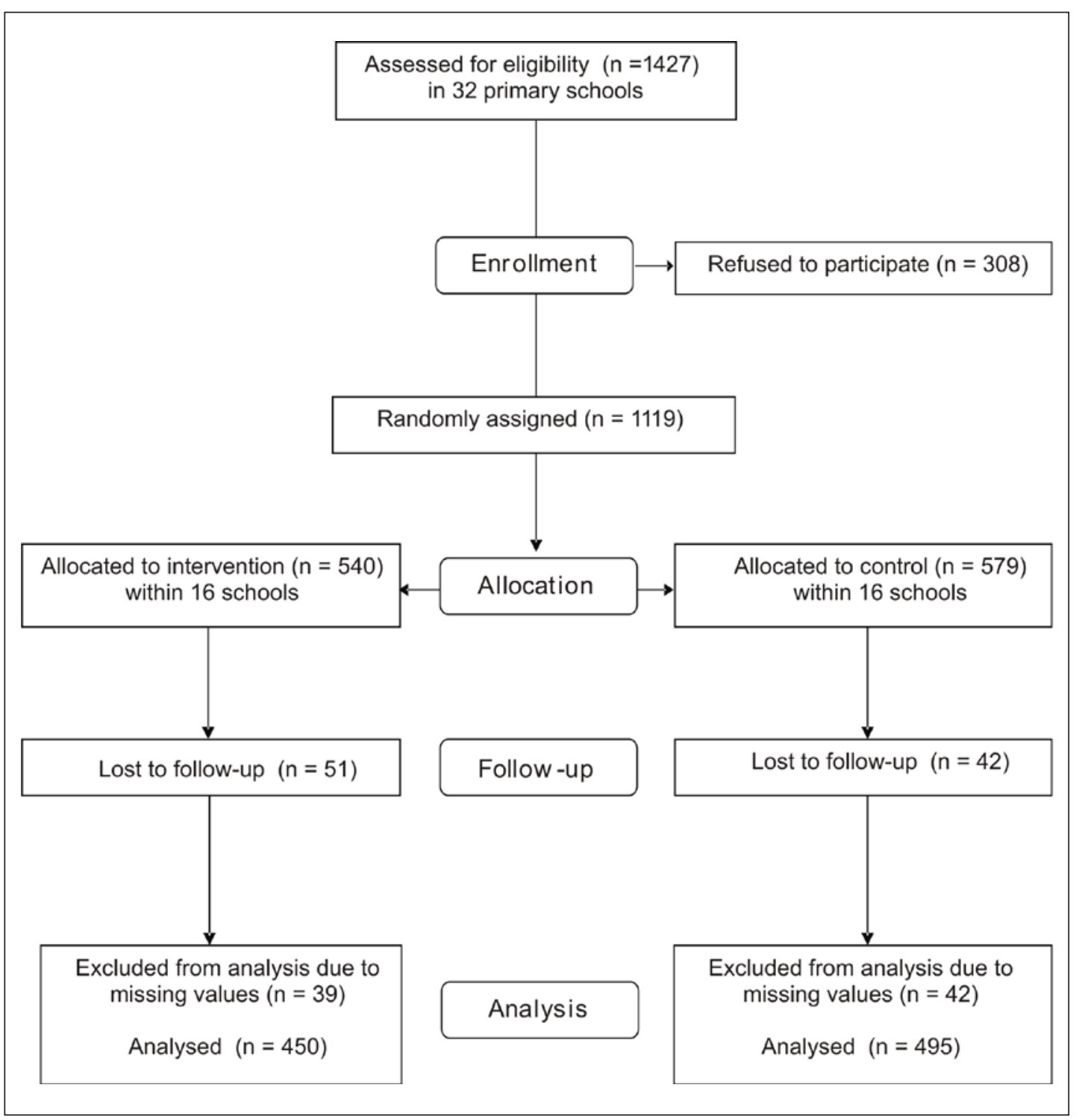

Fig. 1. Flow chart for enrollment and follow-up in URMEL-ICE.

In summary, 64 classes of 32 schools were assessed to be eligible and agreed to participate (fig. 1).

The randomisation aimed at creating two groups (intervention and control) with an equal number of schools. The procedure was performed in a blind manner.

Due to considerable differences between schools, especially in the number of participating pupils and in the proportion of pupils with migration background (5-94\%), a stratified randomisation procedure was chosen. This resulted in two groups of the same size, but could not prevent unequal proportions of pupils with migration background (table 1).

From the eligible 1,427 children 308 refused to participate. This resulted in 540 pupils in 16 intervention schools and 579 pupils in 16 control schools, from whom 51 and 42 children respectively were lost to follow-up. The final dataset included 450 children in the intervention group and 495 children in the control group after excluding 39 and 42 children respectively due to missing values.

Parents were informed at parent-teacher conferences and provided signed written informed consent for their children to participate in assessments and clinical investigations. The study was approved by the ethics committee of Ulm University. 
Table 1. Baseline characteristics of participants

\begin{tabular}{|c|c|c|c|}
\hline & $\begin{array}{l}\text { Control } \\
(n=495)\end{array}$ & $\begin{array}{l}\text { Intervention } \\
(\mathrm{n}=450)\end{array}$ & $\mathrm{p}$ value \\
\hline \multicolumn{4}{|l|}{ Children's characteristics } \\
\hline Male, n (\%) & $258(52.1)$ & $248(55.1)$ & 0.357 \\
\hline Age, mean (SD), years & $7.53(0.42)$ & $7.61(0.42)$ & 0.002 \\
\hline Migration background, n (\%) & $182(36.8)$ & $130(28.9)$ & 0.010 \\
\hline Time lag between $t_{0}$ and $t_{1}$, mean (SD), days & $463(67.3)$ & $427(60.7)$ & $<0.001$ \\
\hline BMI, mean (SD), kg/m² & $16.24(2.10)$ & $16.23(2.25)$ & 0.944 \\
\hline BMI z score, mean (SD) a & $0.05(0.97)$ & $0.00(1.04)$ & 0.457 \\
\hline Skinfold thickness triceps, mean (SD), mm & $14.27(5.86)$ & $14.49(6.37)$ & 0.568 \\
\hline Skinfold thickness subscapular, mean (SD), mm & $7.98(4.03)$ & $8.22(4.64)$ & 0.390 \\
\hline Waist circumference, mean (SD), cm & $59.20(6.38)$ & $59.66(6.65)$ & 0.271 \\
\hline \multicolumn{4}{|l|}{ Parents' characteristics } \\
\hline Mothers' BMI, mean (SD), kg/m² & $23.07(4.25)$ & $24.90(4.50)$ & 0.028 \\
\hline Fathers' BMI, mean (SD), kg/m² & $26.08(3.41)$ & $25.96(3.01)$ & 0.587 \\
\hline Mothers with schooling > 10 years, n (\%) & $162(33.5)$ & $85(19.3)$ & $<0.001$ \\
\hline Fathers with schooling $>10$ years, $\mathrm{n}(\%)$ & $200(42.6)$ & $114(26.8)$ & $<0.001$ \\
\hline
\end{tabular}

\section{Intervention}

Researchers and experienced teachers worked together in the development of the URMEL-ICE intervention. The researchers determined the study design and the behavioural goals by referring to the recommendations found in scientific literature. Experienced teachers who were interested in working with the researchers on the subject of school-based overweight prevention contributed to the study by offering ideas for implementation in the everyday classroom setting.

The intervention was carried out by the classroom teachers themselves during the second-grade school year. It was important to anchor the contents within the existing curriculum (mainly social studies) in order to ensure programme implementation without additional personnel or materials in everyday teaching.

URMEL-ICE focused on health-promoting behaviour change in three areas: drinking sugar-sweetened beverages, spending time with screen media and being physically active. Main issues were the following: drinking water instead of soft drinks, discovering 'hidden' sugar in drinks, encouraging everyday physical activities, engaging in leisure activities without TV, learning about local sport and leisure facilities.

Social cognitive theory provided the framework for the methodical approach: As self-efficacy is assumed to be crucial for behaviour change, we emphasized action alternatives (how to substitute a healthier behaviour for a less healthy one) as well as goals which could be easily accomplished [24]. Furthermore, modified teaching should facilitate more physical activity in the classroom; suggestions for involving parents were also provided.

The URMEL-ICE-intervention consists of material for 1 school year including 29 teaching units (each 30-60 min), 2 short blocks of physical activity exercises a day (each 5-7 min), 6 family homework lessons (tasks that cannot be accomplished by the child himself without the help of a parent) and materials for the training and information of the parents.

Teachers took part in four training sessions ( $2.5 \mathrm{~h}$ each) to familiarise themselves with the basic concept of the intervention and the relevant materials. Teachers and schools had no direct costs to cover (for materials or for additional teaching time). However, in terms of indirect costs for the schools, the intervention required 29 regular teaching units mainly in social sciences during 1 school year (that corresponds to the weekly working time of teachers) and additionally $10 \mathrm{~h}$ of training sessions. From the perspective of the intervention provider costs were limited to personnel costs of the teacher trainings sessions and material costs of the intervention materials (one folder per teacher). 
Brandstetter et al.: Overweight Prevention in Primary Schools

\section{Measurement}

The study included a baseline assessment at the end of first grade or at the beginning of grade 2 between May and October 2006 (t0), followed by the intervention between October 2006 and July 2007 during grade 2, and a follow-up assessment at the beginning of grade 3 between September and December 2007 (t1). Amongst other measurements a physical examination (anthropometry) and a parental questionnaire (sociodemographic data, behaviour, parents' anthropometry) were included. Each participating class went on a field trip to the Clinical Study Center of the Children's Hospital in order to collect the anthropometric data.

\section{Anthropometry}

During the physical examinations, anthropometric measures were assessed by trained medical staff at the out-patient clinic of Ulm Children's Hospital in a standardised manner. Height was measured to the nearest $0.1 \mathrm{~cm}$ (Ulm stadiometer, Busse Design, Ulm, Germany) and weight to the nearest $0.1 \mathrm{~kg}$ on a calibrated balance beam scale (Seca, Hamburg, Germany) wearing only underclothes. BMI was calculated as weight $(\mathrm{kg})$ divided by height ${ }^{2}\left(\mathrm{~m}^{2}\right)$. BMI z score was determined using age and sex-specific BMI charts for Germany [5]. Subscapular skinfold thickness (below the tip of the scapula with the fold running at an angel of $45^{\circ}$ downwards from the spine) and triceps skinfold thickness (on the left arm halfway between the inferior border of the olecranon and the tip of the acromion process) were measured with a Lange skinfold calliper (Santa Cruz, CA, USA). The average value out of 3 measurements was used for analyses in both variables. Waist circumference was provided by the mean of 2 measurements at umbilicus level in $0.1 \mathrm{~cm}$.

\section{Behaviour}

Children's behaviours that were targeted by the intervention were assessed by parental questionnaires. As there are not any validated instruments assessing these specific behaviours in German, some items were adapted from the KiGGS survey [25, 26]. Items were answered using a 5-point Likert scale: frequency of consuming sugar-sweetened beverages at school and at home, frequency of playing outdoors, frequency of participating in club sport and in other sport activity (nearly every day, 3-5 times a week,1-2 times a week, less than 1 time a week, never), and time spent watching TV on weekdays and weekends (never, about $30 \mathrm{~min} /$ day, about 1-2 h/day, about 3-4 h/day, more than $4 \mathrm{~h} /$ day). Improvement (worsening) of health behaviour was defined as consuming less (more) often sugar-sweetened beverages, being more (less) often physically active and watching less (more) TV compared to the baseline measurement.

\section{Migration Background and Parental Education}

Migration background was assumed if at least one parent was born abroad or if at least one parent mainly spoke a foreign language during the children's first years of life. This definition should also include people who were born in Germany but still follow their traditional lifestyle, such as second-generation immigrants.

Parental education can serve as a surrogate for socio-economic status to differentiate between lower and higher social class [27]. Higher education was assumed for schooling of more than 10 years.

\section{Process Evaluation}

Teachers' implementation of the intervention was assessed by questionnaires at the end of the school year. Each teaching unit was listed and teachers provided information whether it was used in class or not.

\section{Statistical Analysis}

To check for imbalance in baseline characteristics between the randomisation groups we applied chi square and Wilcoxon tests.

Differences of BMI, triceps and subscapular skinfold thickness as well as of waist circumference between baseline and follow-up assessment according to intervention status were calculated using linear regression models. To account for the cluster-randomised design we additionally applied multi-level analyses with class on the second-level and subject on the first-level domain. The estimated regression coefficients of the models correspond to the differences between control and intervention group. At baseline age, migration background, mothers' BMI, parental education and time between $\mathrm{t} 0$ and $\mathrm{t} 1$ varied significantly between intervention and control group (table 1). However, only adjustment for the time lag changed the outcome considerably. Therefore, only time between $\mathrm{t} 0$ and $\mathrm{t} 1 \mathrm{was}$ included in a second model.

All analyses were carried out using SAS 9.1 (Cary, NC, USA). 
Table 2. Differences between control and intervention group after the intervention: multi-level analyses of BMI and secondary outcomes

\begin{tabular}{|c|c|c|c|c|c|c|}
\hline & \multirow[t]{2}{*}{$\mathrm{n}$} & \multirow{2}{*}{$\begin{array}{l}\text { Baseline } \\
\text { value } \\
\text { mean (SD) }\end{array}$} & \multicolumn{2}{|c|}{$\begin{array}{l}\text { Model } 1 \text { adjusted for } \\
\text { baseline value }\end{array}$} & \multicolumn{2}{|c|}{$\begin{array}{l}\text { Model } 2 \text { adjusted for } \\
\text { baseline value and time } \\
\text { lag between } t_{0} \text { and } t_{1}\end{array}$} \\
\hline & & & estimate & $95 \%$ CIa & estimate & $95 \% \mathrm{CI}^{\mathrm{a}}$ \\
\hline BMI, $\mathrm{kg} / \mathrm{m}^{2}$ & 945 & $16.23(2.17)$ & -0.06 & -0.21 to 0.10 & -0.01 & -0.14 to 0.13 \\
\hline \multicolumn{7}{|l|}{ Skinfold thickness, mm } \\
\hline Triceps & 945 & $14.37(6.11)$ & -0.50 & -1.53 to 0.53 & -0.26 & -1.27 to 0.76 \\
\hline Subscapular & 945 & $8.10(4.33)$ & -0.64 & -1.25 to -0.02 & -0.60 & -1.25 to 0.05 \\
\hline Waist circumference, $\mathrm{cm}$ & 945 & $59.42(6.51)$ & -0.85 & -1.59 to -0.12 & -0.61 & -1.26 to 0.04 \\
\hline
\end{tabular}

a95\% CI. Regression coefficients correspond to the differences between control and intervention group. Negative estimates indicate a favourable intervention effect.

\section{Results}

Baseline characteristics of the study population are shown in table 1. Of the participants 506 (53.5\%) were boys and 439 (46.5\%) were girls. There were statistically significant differences between the age of the intervention and control group (7.53 vs. 7.61 years), percentage with migration background (36.8 vs. 28.9\%), some parental characteristics and time lag between $\mathrm{t} 0$ and $\mathrm{t} 1$ (463 vs. 427 days). In contrast, baseline values of anthropometric measures did not vary notably.

30 of 32 teachers in the intervention classes provided data about implementation. 75\% implemented two thirds or more of the required 29 teaching units over the intervention school year; on average 23.1 (SD = 6.3) teaching units were used.

The crude proportions (\%) of children who improved versus worsened their behaviour according to the intervention targets are shown in fig. 2. Overall, there were more children who improved their health behaviours over 1 year than worsened them. The intervention group revealed a higher percentage of children with an improvement and a lower percentage with a worsening of the health-relevant behaviours compared to the control group. This applies to all aspects of behaviour except to participation in club sports.

fig. 3 illustrates the unadjusted change in mean values of BMI, waist circumference and triceps and subscapular skinfold thickness. In the intervention group the increases in waist circumference, triceps and subscapular skinfold thickness were reduced in a consistent manner compared to the control group.

Applying multi-level analyses to account for the cluster design revealed a similar pattern (table 2). The primary outcome BMI was not influenced by the intervention. However, secondary outcomes showed statistically significant estimates: Differences between intervention and control group were -0.64 (95\% CI -1.25 to -0.02$) \mathrm{mm}$ for subscapular skinfold thickness and -0.85 (95\% CI-: -1.59 to -0.12$) \mathrm{cm}$ for waist circumference. After adjustment for time lag between $t 0$ and $t 1$, these associations were reduced and lost their statistical significance (model 2 in table 2 ). 

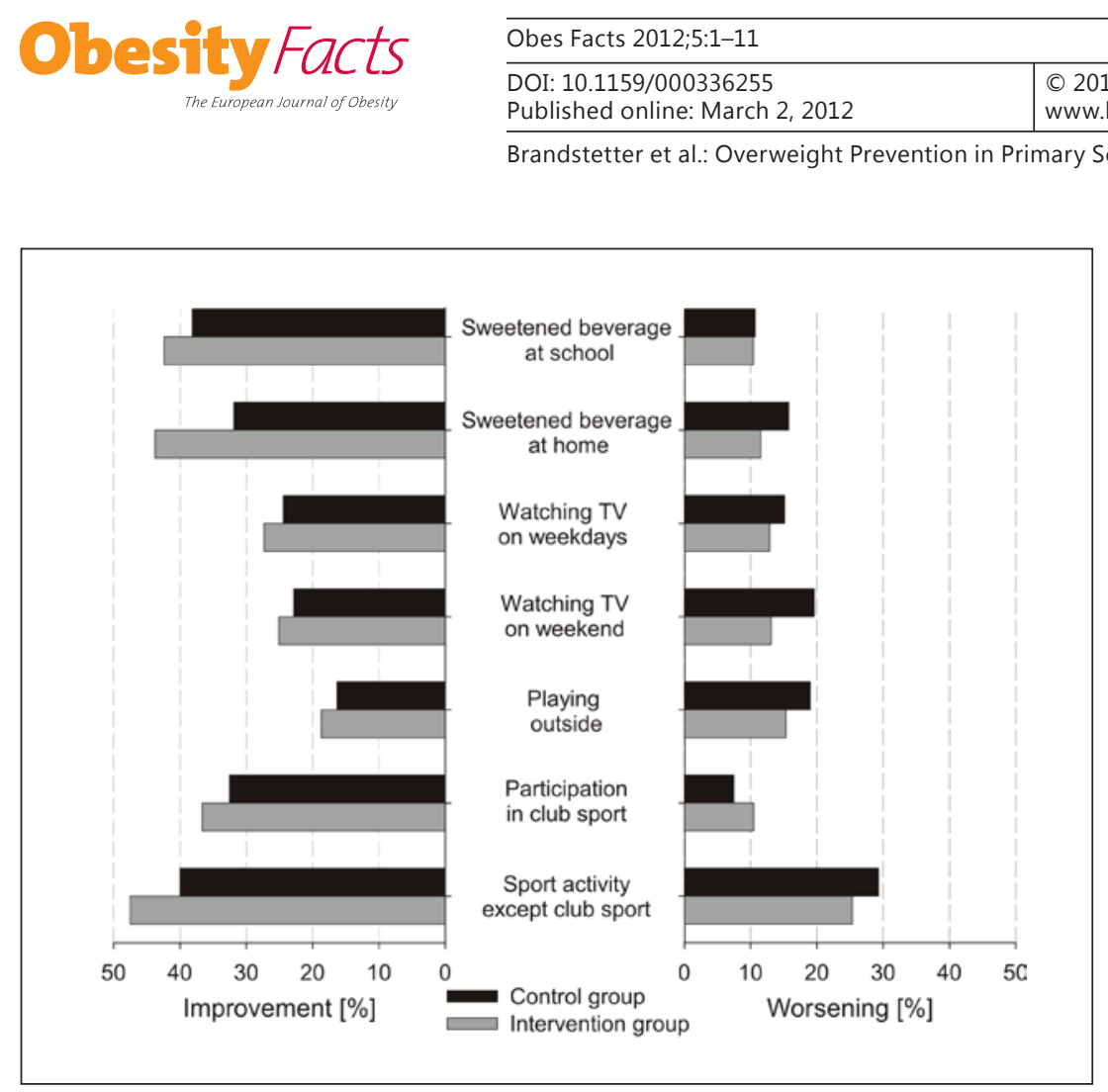

Fig. 2. Proportion (\%) of participants changing their behaviour between baseline and follow-up according to intervention status.

\section{Discussion}

URMEL-ICE contributes to the field of randomised school-based studies on overweight prevention. There are several methodological strengths of our study which should be mentioned. URMEL-ICE is the largest randomised-controlled, school-based overweight prevention study in Germany. It is adequately powered, with a high rate of participation and a low rate of drop-outs to the follow-up measurement. In our sample both the proportion of children with migration background (U. Ellert, for the KiGGS-Study, personal communication, January 19, 2009) and the prevalence of overweight [4] are representative for elementary school children in Germany. We used multiple parameters to assess anthropometry. All measurements were gathered by trained staff in Ulm Children's Hospital.

The differences in the rate of children with migration background between schools (ranging from 5\% to 94\%) were taken into account by choosing a multi-level approach.

Although the intervention did not influence BMI which was the primary outcome variable, it resulted in a reduction of subscapular skinfold thickness and waist circumference. Thus, this study is unfortunately in line with literature, suggesting that currently prevention programmes achieve only minor effects [28].

Differential intervention effects were found for the different anthropometric measures. Subscapular skinfold thickness and waist circumference were slightly affected by the intervention, but triceps skinfold thickness and BMI were not. Some intervention studies have described such differences in the effects on anthropometric parameters: Vandongen et al. [29] reported a significant decrease in triceps skinfold thickness resulting from a physical fitness intervention over 1 school year but did not identify changes to subscapular skinfold thickness, percentage of body fat and BMI, Kain et al. [30] found a favourable effect of a combined physical activity and nutrition intervention on BMI and waist circumference, but not on triceps skinfold thickness in boys. 


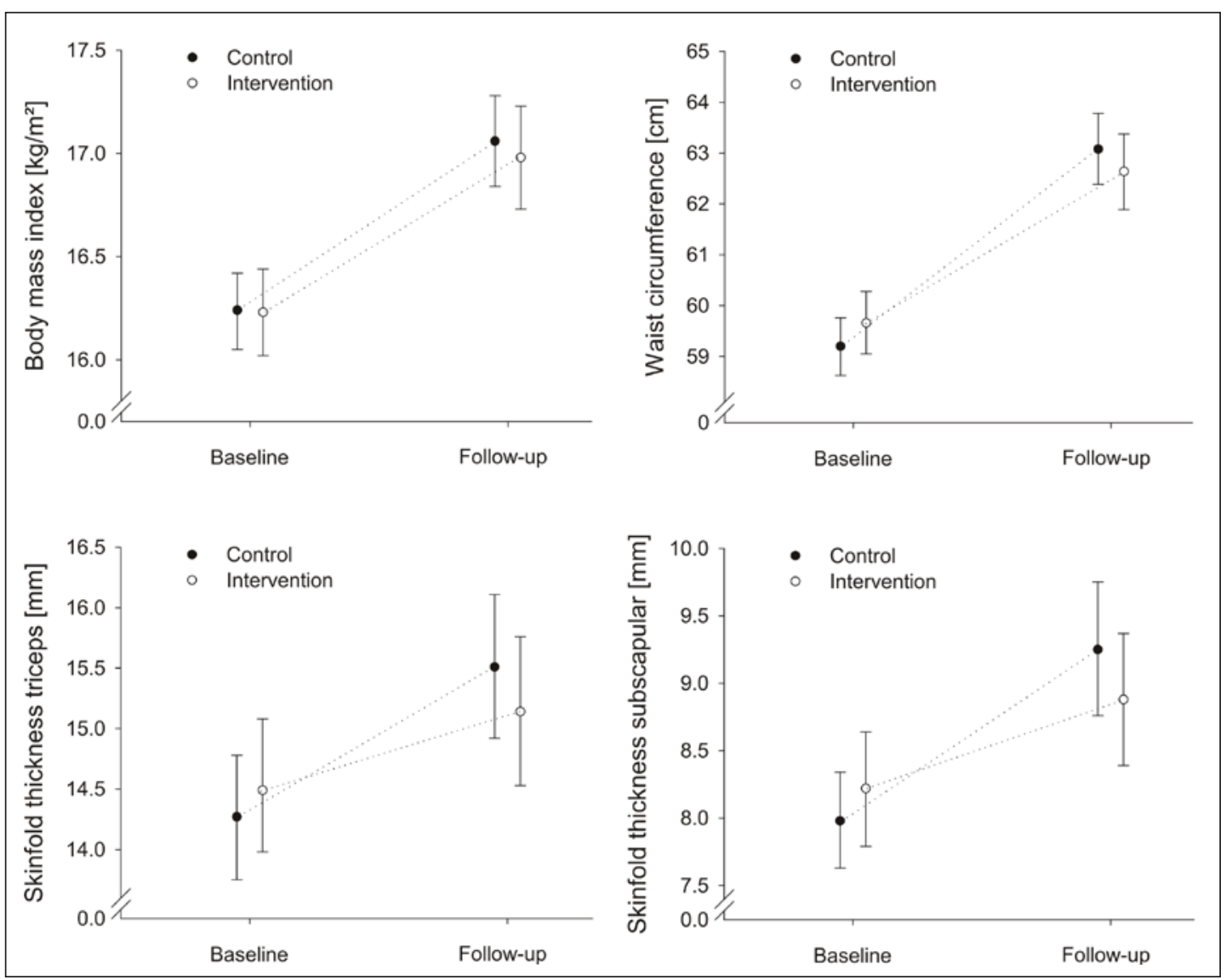

Fig. 3. Anthropometric measures at baseline and follow-up according to intervention status. Unadjusted mean values and 95\% confidence limits of body mass index, waist circumference, skinfold thickness triceps and skinfold thickness subscapular.

Whereas BMI reflects both fat-free and fat mass, skinfold thickness and waist circumference are more specific measures of body fat distribution. The overall convergence in three anthropometric measures - subscapular and triceps skinfold thickness and waist circumference - indicates that the intervention resulted in a shift of body composition towards less fat (and possibly more muscle) mass. Assuming this, the activity-enhancing components of the intervention would have been especially important and successful.

Overall, estimates of the intervention effect on anthropometric parameters were smaller among children with migration background compared to the ones without (data not shown). These difficulties in reaching socially disadvantaged children within schools are well known limitations of such efforts and are in line with results of other studies in Germany $[31,32]$.

Intervention and control group differed in the time lag between the two points of measurements. Organisational constraints impeded that classes were examined at followup following the same chronological order as at baseline. In addition, time periods for investigating the children were rather long: 6 months at baseline and 4 months at follow-up. This was necessary since we chose a hospital-based setting for the investigations including blood analysis and sophisticated investigations like ultrasound measurements and evaluation of cardiac function. Assuming an influence of this time lag on the intervention effects, we 
analysed our data with an adjustment for the time lag. This analysis resulted only in a marginal reduction of the effects on subscapular skinfold thickness and in a stronger reduction of positive changes in waist circumference.

A previous study showed that the summer break is a critical phase for maintaining behaviour changes acquired at school [33]. The intervention effects may have been subdued since the follow-up measurements in our study took place after a 6-week summer break.

Unlike the control group, the children in the intervention group showed changes in their behaviour by consuming less sweetened beverages and being more physically active.

Results concerning club sport participation remain unclear. The local availability of sports facilities may affect children's physical activity, but such environmental measures were beyond the means of this school-based intervention. Overall, the demonstrated changes are probably due to the intervention, even if the measures used were not designed to detect intervention effects. However, it cannot be excluded that parents of the children in the intervention group may have caused a response shift bias [34].

As Gonzalez-Suarez et al. [35] stated in their meta-analysis on school-based obesity prevention programmes there are many factors out of researchers' control that may influence the effectiveness of interventions. Compliance of teachers and the implementation of the intervention are crucial to the success of the study. Thus, we decided to develop the URMEL-ICE intervention according to the curricular contents of elementary school in order to facilitate regular implementation for teachers and to ensure that no additional personnel or lessons were required. Over the course of 1 school year we found implementation rates that were acceptable, but nevertheless could still be improved.

Recently, prevention measures were described including high amounts of extra physical education. In a study by Kriemler et al. [36] in Switzerland 2 extra lessons weekly were provided and resulted in small, but significant changes in skinfold thickness and BMI. The intervention of another German study scheduled even 3 extra lessons of physical education and showed positive effects on children's physical fitness, but not on BMI-SDS and measures of body composition [37]. Obviously, these are highly desirable and powerful approaches.

However, aspects of feasibility are crucial and must be considered.

There are examples of short-term prevention programmes that were effective initially yet could not maintain their success at later follow-ups [32, 38, 39]. Over the course of the years effects attenuated or were restricted to subgroups.

Thus, there is a need for prevention programmes, which run long term and can be applied comprehensively, in spite of schools' limited financial and personnel resources.

The URMEL-ICE intervention is an example of a programme that complies with the given requirements. However, it should be expanded in terms of intervention duration to make it more effective. An intervention period of more than 1 school year may increase the possibility that behaviour changes are reflected in improvements in children's body composition.

Obviously, to succeed in childhood overweight prevention in the long run, school-based, teacher-centred interventions are just one approach. The development of health promoting environments still remains highly important.

In conclusion, the 1 year school-based, curriculum-integrated intervention presented here showed no effects on children's BMI. However, there is a tendency for positive changes in subscapular skinfold thickness and waist circumference, which in terms of populationwide, school-based prevention might nevertheless be of importance. 


\section{Acknowledgements}

We would like to thank the members of the URMEL-ICE study group and all teachers, parents and children, who participated in this study.

This study has been funded by the Baden-Württemberg Stiftung (Stuttgart, Germany).

\section{Disclosure Statement}

The authors declare that they have no conflict of interest.

\section{References}

1 Ogden CL, Carroll MD, Curtin LR, Lamb MM, Flegal KM: Prevalence of high body mass index in US children and adolescents, 2007-2008. JAMA 2010;303:242-249.

- 2 Janssen I, Katzmarzyk PT, Boyce WF, Vereecken C, Mulvihill C, Roberts C, Currie C, Pickett W, Nemeth A, Ojala K, Ravens-Sieberer U, Todd J, Woynarowska B: Comparison of overweight and obesity prevalance in school-aged youth from 34 countries and their relationships with physical activity and dietary patterns. Obes Rev 2005;6:123-132.

- 3 Nagel G, Wabitsch M, Galm C, Berg S, Brandstetter S, Fritz M, Klenk J, Peter R, Prokopchuk D, Steiner R, Stroth S, Wartha O, Weiland SK, Steinacker J: Secular changes of anthropometric measures for the past 30 years in South-West Germany. Eur J Clin Nutr 2009;63:1440-1443.

4 Kurth B-M, Schaffrath Rosario A: The prevalence of overweight and obese children and adolescents living in Germany. Results of the German Health Interview and Examination Survey for Children and Adolescents (KiGGS) (in German). Bundesgesundheitsblatt 2007;50:736-743.

5 Kromeyer-Hauschild K, Wabitsch M, Kunze D, Geller F, Geiß HC, Heese V, von Hippel A, Jaeger U, Johnsen D, Korte W, Menner K, Müller G, Müller JM, Niemann-Pilatus A, Remer T, Schaefer F, Wittchen H-U, Zabransky S, Zellner K, Ziegler A, Hebebrand J: Percentiles of body mass index in children and adolescents evaluated from different regional German studies (in German). Monatsschr Kinderheilkd 2001;149:807-818.

- 6 Rokholm B, Baker JL, Sorensen TIA: The levelling off of the obesity epidemic since the year 1999-a review of evidence and perspectives. Obes Rev 2010;11:835-846.

- 7 Kelder SH, Osganian SK, Feldman HA, Webber LS, Parcel GS, Leupker RV, Wu MC, Nader PR: Tracking of physical and physiological risk variables among ethnic subgroups from third to eighth grade: the Child and Adolescent Trial for Cardiovascular Health Cohort Study. Prev Med 2002;34:324-333.

- 8 Wright CM, Emmett PM, Ness AR, Reilly JJ, Sherriff A: Tracking of obesity and body fatness through midchildhood. Arch Dis Child 2010;95:612-617.

- 9 Whitaker RC, Wright JA, Pepe MS, Seidel KD, Dietz WH: Predicting obesity in young adulthood from childhood and parental obesity. N Engl J Med 1997;337:869-873.

-10 Latzer Y, Edmunds L, Fenig S, Golan M, Gur E, Hochberg Z, Levin-Zamir D, Zubery E, Speiser PW, Stein D: Managing chilhood overweight: behavior, family, pharmacology, and bariatric surgery interventions. Obes Res 2009;17:411-423.

11 Stice E, Heather S, Marti CN: A meta-analytical review of obesity prevention programs for children and adolescents: The skinny on interventions that work. Psychol Bull 2006;132:667-691.

12 Summerbell CD, Waters E, Edmunds LD, Kelly S, Brown T, Campbell KJ: Interventions for preventing obesity in children. Cochrane Database Syst Rev 2005;CD001871.

13 Kamath CC, Vickers KS, Ehrlich A, McGovern L, Johnson J, Singhal V, Paulo R, Hettinger A, Erwin PJ, Montori VM: Behavioral interventions to prevent childhood obesity: a systematic review and metaanalyses of randomized trials. J Clin Endocrinol Metab 2008;93:4606-4615.

14 Kropski JA, Keckley PH, Jensen GL: School-based obesity prevention programs: an evidence-based review. Obes Res 2008;16:1009-1018.

15 Gortmaker SL, Peterson K, Wiecha J, Sobol AM, Dixit S, Fox MK, Laird N: Reducing obesity via a school-based interdisciplinary intervention among youth: Planet Health. Arch Pediatr Adolesc Med 1999;153:409-18.

$\checkmark 16$ Robinson TN: Reducing children's television viewing to prevent obesity: a randomized controlled trial. JAMA 1999;282:1561-1567.

17 James J, Thomas P, Cavan D, Kerr D: Preventing childhood obesity by reducing consumption of carbonated drinks: cluster randomised controlled trial. BMJ 2004;328:1237.

18 Pyle SA, Sharkey J, Yetter G, Felix E, Furlong MJ, Poston WSC: Fighting an epidemic: the role of schools in reducing childhood obesity. Psychol Schools 2006;43:361-376.

19 He M, Piché L, Beynon C, Kurtz J, Harris S: Screen-related sedentary behaviours of school-aged children: principals' and teachers' perspectives. Health Educ J 2011;70:32-38. 
Bauer KW, Patel A, Prokop L, Austin SB: Swimming upstream: faculty and staff members from urban middle schools in low-income communities describe their experience implementing nutrition and physical activity initiatives. Prev Chronic Dis 2006;3:1-17.

21 Han SS, Weiss B: Sustainability of teacher implementation of school-based mental-health programs. J Abnorm Child Psychol 2005;33:665-679.

-22 Nething K, Stroth S, Wabitsch M, Galm C, Rapp K, Brandstetter S, Berg S, Kresz A, Wartha O, Steinacker JM: Primary prevention of sequelae of adiposity in children and adolescents (in German). Dtsch Z Sportmed 2006;57:42-45.

23 Nagel G, Wabitsch M, Galm C, Berg S, Brandstetter S, Fritz M, Klenk J, Peter R, Prokopchuk D, Steiner R, Stroth S, Wartha O, Weiland SK, Steinacker J: Determinants of obesity in the Ulm Research on Metabolism, Exercise and Lifestyle in Children (URMEL-ICE). Eur J Pediatr 2009;168:1259-1267. Bandura A: Social cognitive theory: an agentic perspective. Annu Rev Psychol 2001;52:1-26.

-25 Opper E, Worth A, Wagner M, Bös K: The module 'Motorik' in the German Health Interview and Examination Survey for Children and Adolescents (KiGGS). Motor fitness and physical activity of children and young people (in German). Bundesgesundheitsblatt 2007;50:879-888.

-26 Lampert T, Sygusch R, Schlack R: Use of electronic media in adolescence. Results of the German Health Interview and Examination Survey for Children and Adolescents (KiGGS) (in German). Bundesgesundheitsblatt 2007;50:643-652.

-27 Lamerz A, Kuepper-Nybelen J, Wehle C, Bruning N, Trost-Brinkhues G, Brenner H, Herpertz-Dahlmann B: Social class, parental education, and obesity prevalence in a study of six-year-old children in Germany. Int J Obes 2005;29:373-380.

28 Thomas H: Obesity prevention programs for children and youth: why are their results so modest? Health Educ Res 2006;21:783-795.

-29 Vandongen R, Jenner DA, Thompson C, Taggart AC, Spickett EE, Burke V, Beilin LJ, Dunbar DL: A controlled evaluation of a fitness and nutrition intervention program on cardiovascular health in 10-to 12-year-old children. Prev Med 1995;24:9-22.

-30 Kain J, Uauy R, Albala, Vio F, Cerda R, Leyton B: School-based obesity prevention in Chilean primary school children: methodology and evaluation of a controlled study. Int J Obes 2004;28:483-493.

-31 Muckelbauer R, Libuda L, Clausen K, Toschke AM, Reinehr T, Kersting M: Immigrational background affects the effectiveness of a school-based overweight prevention program promoting water consumption. Obes Res 2010;18:528-534.

-32 Plachta-Danielzik S, Landsberg B, Lange D, Seiberl J, Müller MJ: Eight-year follow-up of school-based intervention on childhood overweight - the Kiel Obesity Prevention Study. Obes Facts 2011;4:35-43.

-33 Carrel AL, Clark RR, Peterson S, Eickhoff J, Allen DB: School-based fitness changes are lost during the summer vacation. Arch Pediatr Adolesc Med 2007;161:561-564.

34 Rohs FR, Langone CA, Coleman HK: Response shift bias: A problem in evaluating nutrition training using self-report measures. J Nutr Educ 2001;33:165-170.

-35 Gonzalez-Suarez C, Worley A, Grimmer-Somers K, Dones V: School-based interventions on childhood obesity. A meta-analysis. Am J Prev Med 2009;37:418-427.

-36 Kriemler S, Zahner L, Schindler C, Meyer U, Hartmann T, Hebestreit H, Brunner-La Rocca HP, van Mechelen W, Puder JJ: Effect of school based physical activity programme (KISS) on fitness and adiposity in primary schoolchildren: cluster randomised controlled trial. BMJ 2010;340:c785.

37 Walther C, Gaede L, Adams V, Gelbrich G, Leichtle A, Erbs S, Sonnabend M, Fikenzer K, Körner A, Kiess W, Bruegel M, Thiery J, Schuler G: Effect of increased exercise in school children on physical fitness and endothelial progenitor cells: a prospective randomized trial. Circulation 2009;120:2251-2259.

38 James J, Thomas P, Kerr D: Preventing childhood obesity: two year follow-up results from th chopps programme in school. BMJ 2007;335.

-39 Plachta-Danielzik S, Pust S, Asbeck I, Czerwinski-Mast M, Langnäse K, Fischer C, Bosy-Westphal A, Kriwy P, Müller MJ: Four-year follow up of school-based intervention on overweight children: the KOPS study. Obes Res 2007;15:3159-3169. 